\title{
Corrigendum to "Recommendations from the United European Gastroenterology evidence-based guidelines for the diagnosis and therapy of chronic pancreatitis" [Pancreatology 18(8) (2018) 847-854]
}

J.E. Dominguez-Munoz ${ }^{\text {a, * }}$, A.M. Drewes ${ }^{b}$, B. Lindkvist ${ }^{c}$, N. Ewald ${ }^{\text {d }}$, L. Czakó ${ }^{e}$, J. Rosendahl ${ }^{\mathrm{f}}$, J.M. Löhr ${ }^{\mathrm{g}}$, HaPanEU/UEG Working Group

${ }^{a}$ Department of Gastroenterology and Hepatology, Health Research Institute, University Hospital of Santiago de Compostela, Spain

${ }^{\mathrm{b}}$ Centre for Pancreatic Diseases, Department of Gastroenterology, Aalborg University Hospital, Denmark

' Institute of Medicine, Sahlgrenska Academy, University of Gothenburg, Gothenburg, Sweden

d Department of Internal Medicine, General Hospital Luebbecke-Rahden Luebbecke, Justus Liebig University Giessen, Giessen, Germany

e First Department of Medicine, University of Szeged, Szeged, Hungary

${ }^{\mathrm{f}}$ Department of Internal Medicine I, Martin Luther University, Halle (Saale), Germany

g Center for Digestive Diseases, Karolinska University Hospital, Stockholm, Sweden

The authors regret that an author name was incorrectly spelled as "Okhlobystiy AV". The correct spelling is "Okhlobystin AV". The authors would like to apologise for any inconvenience caused.

DOI of original article: https://doi.org/10.1016/j.pan.2018.09.016.

* Corresponding author.

E-mail address: Juan.Enrique.Dominguez.Munoz@sergas.es(J.E. DominguezMunoz). 